\title{
AMG 531, a Thrombopoiesis-Stimulating Protein, for Chronic ITP
}

\author{
James B. Bussel, M.D., David J. Kuter, M.D., D.Phil., James N. George, M.D., \\ Robert McMillan, M.D., Louis M. Aledort, M.D., George T. Conklin, M.D., \\ Alan E. Lichtin, M.D., Roger M. Lyons, M.D., Jorge Nieva, M.D., \\ Jeffrey S. Wasser, M.D., Israel Wiznitzer, M.D., Reggie Kelly, B.S., \\ Chien-Feng Chen, Ph.D., and Janet L. Nichol, M.S.
}

A BSTRACT

From the New York Presbyterian Hospital, New York (J.B.B.); Massachusetts Genera Hospital, Boston (D.J.K.); University of Oklahoma Medical Center, Oklahoma City (J.N.G.); Scripps Cancer Center, La Jolla, CA (R.M., J.N.); Mount Sina Medical Center, New York (L.M.A.) Diagnostic Clinic of Houston, Houston (G.T.C.); Cleveland Clinic Foundation Cleveland (A.E.L.); Hematology-Oncology Associates of South Texas, San Antonio, TX (R.M.L.); DeQuattro Community Cancer Center, Manchester, CT (J.S.W.) Broward General Medical Center, For Lauderdale, FL (I.W.); and Amgen Thousand Oaks, CA (R.K., C.-F.C., J.L.N.) Address reprint requests to Dr. Bussel at Weill Cornell University, Division of Pediatric Hematology, Payson 609, 525 E. 68th St., New York, NY 10021, or at jbussel@med.cornell.edu.

N Engl J Med 2006;355:1672-81.

Copyright (c) 2006 Massachusetts Medical Society.

\section{BACKGROUND}

Most current treatments for chronic immune thrombocytopenic purpura (ITP) act by decreasing platelet destruction. In a phase 1-2 study, we administered a thrombopoiesis-stimulating protein, AMG 531, to patients with ITP.

\section{METHODS}

In phase 1, 24 patients who had received at least one treatment for ITP were assigned to escalating-dose cohorts of 4 patients each and given two identical doses of AMG 531 ( 0.2 to $10 \mu \mathrm{g}$ per kilogram of body weight). In phase 2, 21 patients were randomly assigned to receive six weekly subcutaneous injections of AMG 531 (1, 3, or $6 \mu$ g per kilogram) or placebo. The primary objective was to assess the safety of AMG 531; the secondary objective was to evaluate platelet counts during and after treatment.

\section{RESULTS}

No major adverse events that could be attributed directly to AMG 531 occurred during the treatment period; 4 of 41 patients had transient post-treatment worsening of thrombocytopenia. In phase 1 , a platelet count that was within the targeted range (50,000 to 450,000 per cubic millimeter) and at least twice the baseline count was achieved in 4 of 12 patients given 3, 6, or $10 \mu \mathrm{g}$ of AMG 531 per kilogram. Overall, a platelet count of at least 50,000 per cubic millimeter was achieved in 7 of 12 patients, including 3 with counts exceeding 450,000 per cubic millimeter. Increases in the platelet count were dose-dependent; mean peak counts were 163,000, 309,000, and 746,000 per cubic millimeter with 3, 6, and $10 \mu \mathrm{g}$ of AMG 531 per kilogram, respectively. In phase 2, the targeted platelet range was achieved in 10 of 16 patients treated with 1 or $3 \mu \mathrm{g}$ of AMG 531 per kilogram per week for 6 weeks. Mean peak counts were 135,000, 241,000, and 81,000 per cubic millimeter in the groups that received the $1-\mu \mathrm{g}$ dose, the $3-\mu \mathrm{g}$ dose, and placebo, respectively.

\section{CONCLUSIONS}

AMG 531 caused no major adverse events and increased platelet counts in patients with ITP. (ClinicalTrials.gov number, NCT00111475.) 
MMUNE THROMBOCYTOPENIC PURPURA (ITP) is an autoimmune disorder in which antiplatelet autoantibodies cause platelet destruction. ${ }^{1-6}$ The annual incidence of ITP in the United States is estimated to be approximately 16,000 cases. $^{1,4}$

The initial treatment for ITP, usually corticosteroids, intravenous immune globulin, or $\mathrm{Rh}_{0}(\mathrm{D})$ immune globulin acts primarily by interfering with platelet destruction. ${ }^{7}$ Other immunomodulatory agents suppress the production of antiplatelet antibodies, but relapse is common when these agents are discontinued. Splenectomy, by contrast, can have lasting effects and even cures the disease in some patients.

There is evidence that platelet production is suboptimal in a substantial proportion of patients with ITP, ${ }^{8-21}$ suggesting that a strategy of increasing platelet production may be effective in managing the disorder. In previous studies, polyethylene glycol-conjugated recombinant human megakaryocyte growth and development factor (PEG-MGDF), a recombinant thrombopoietin, increased platelet counts in four of five patients with ITP. ${ }^{22,23}$ However, antibodies against PEG-MGDF developed in healthy volunteers and in patients with cancer, and the antibodies cross-reacted with endogenous thrombopoietin in the patients, causing severe, persistent thrombocytopenia. ${ }^{24,25}$ As a result, clinical development of PEG-MGDF was stopped.

A novel thrombopoiesis-stimulating protein, AMG 531 (Amgen), has recently been developed. It has no sequence homology with endogenous thrombopoietin, ${ }^{26,27}$ a feature that should preclude the development of cross-reacting antibodies. We conducted a study to evaluate the safety and efficacy of treatment with AMG 531 in patients with ITP.

\section{METHODS}

\section{AMG 531}

AMG 531 is a protein that stimulates thrombopoiesis $^{26}$ (Fig. 1). It consists of disulfide-bonded human IgG1 heavy-chain and kappa light-chain constant regions (an Fc fragment) with two identical peptide sequences linked covalently at residue 228 of the heavy chain with the use of a polyglycine. The Fc component extends the half-life of the molecule in the circulation. The peptide portion was selected by screening libraries of peptides that have

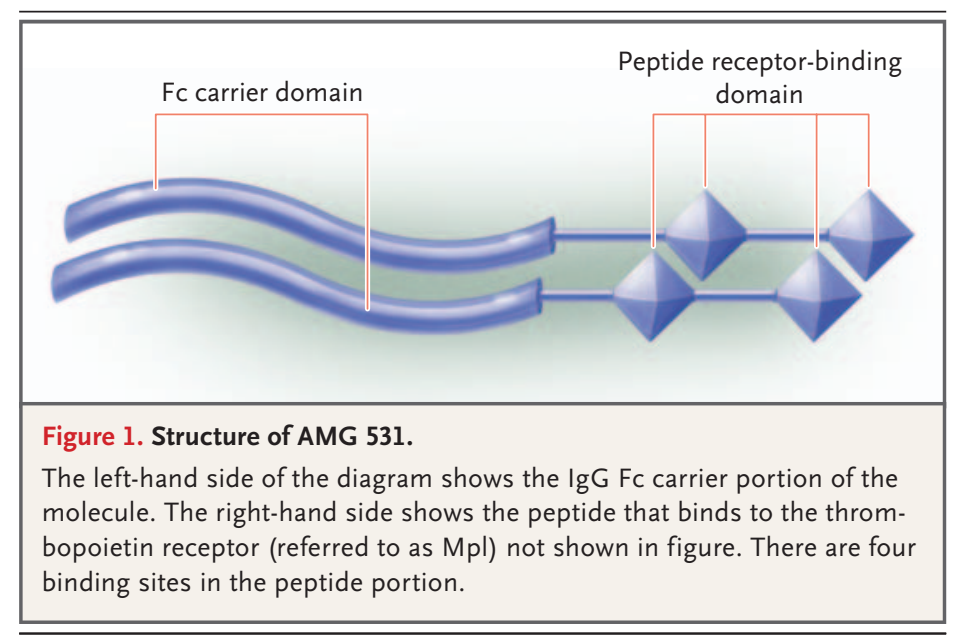

no sequence homology with human thrombopoietin to find one with a tertiary structure that would allow it to bind to and activate the human thrombopoietin receptor, called $\mathrm{Mpl}$. In healthy volunteers, AMG 531, a clear, colorless liquid administered by subcutaneous injection, increased platelet production and platelet counts and did not induce neutralizing or cross-reacting antibodies against thrombopoietin. ${ }^{28}$

\section{PATIENTS}

Nine U.S. centers enrolled patients with chronic ITP in two sequential trials. The institutional review boards at the participating centers approved the protocols, and all patients gave written informed consent before undergoing eligibility screening. Inclusion criteria were an age of 18 to 65 years, a history of ITP (according to the American Society of Hematology guidelines ${ }^{5}$ ) for at least 3 months; one or more prior treatments for ITP; a mean platelet count (the mean value of two counts) of less than 30,000 per cubic millimeter (with no count $>35,000$ per cubic millimeter) for patients not receiving corticosteroids or a mean count of less than 50,000 per cubic millimeter (with no count $>55,000$ per cubic millimeter) for patients receiving corticosteroids. Patients were eligible for enrollment regardless of whether they had undergone splenectomy or whether they were receiving corticosteroid therapy, as long as there had been no changes in the corticosteroid dose or schedule of administration for at least 4 weeks. The following intervals since the last administration of therapy for ITP were required: 2 weeks for intravenous immune globulin, 8 weeks for alkylating agents, 16 weeks for rituximab, and 4 weeks 
for all other treatments. Exclusion criteria were any known risk factor for thromboembolic events, a history of cardiovascular disease, active cancer, and a history of a bone marrow disorder.

\section{STUDY DESIGN}

This study was a multicenter, dose- and schedulefinding trial consisting of two phases (Fig. 2), with no overlap between patients in phase 1 and those in phase 2 .

Phase 1 (conducted from July 1,2002 , to October 13, 2003) was an open-label, dose-escalation trial with sequential cohorts of patients. The primary objective was to assess the safety and tolerability of two injections of AMG 531 in patients with ITP. Secondary objectives were to determine the dose that would result in a platelet count that was within the targeted range $(50,000$ to 450,000 per cubic millimeter) and that was at least twice the baseline count and to determine the adequacy of two AMG 531 injections given within 2 to 3 weeks for achieving this range.

AMG 531 was administered to cohorts of four patients each at doses of $0.2,0.5,1,3,6$, and $10 \mu \mathrm{g}$ per kilogram of body weight. The drug was administered by subcutaneous injection on day 1 , followed by 14 days of observation. Health status, complete blood counts, and blood chemical values were monitored throughout the study. Assays to detect anti-AMG 531 antibodies were performed before treatment, at the end of treatment, and at the end of the study. If the platelet count was less than 50,000 per cubic millimeter on day 15 , a second identical dose was administered. If the platelet count was 50,000 per cubic millimeter or more on day 15 , the second dose was delayed until day 22; if at that time the platelet count remained 50,000 per cubic millimeter or more, the second dose was not given. A data review committee, composed of investigators and Amgen staff members who were not directly involved in the execution of the study, reviewed antibody and other safety data from the current and previous cohorts before treating the next sequential cohort. The protocol required termination of the study if antibodies that cross-reacted with thrombopoietin were detected. After the treatment was completed, patients were followed for an additional 8 weeks.

Phase 2 (conducted from October 6, 2003, to June 17,2004 ) was a double-blind, placebo-controlled evaluation of AMG 531 in patients with ITP. The placebo consisted of the excipients of the
AMG 531 formulation. The objectives were to evaluate the safety of AMG 531 and to determine a weekly dose that would result in a platelet count that was within the targeted range used in phase 1 (50,000 to 450,000 per cubic millimeter) and that was at least twice the baseline count. Patients were randomly assigned to receive AMG 531 at one of three doses $(1,3$, or $6 \mu \mathrm{g}$ per kilogram) or placebo once a week for 6 weeks, with a ratio of AMG 531 assignments to placebo assignments of 4:1. A protocol amendment later eliminated the $6-\mu \mathrm{g}$ cohort; only one patient was randomly assigned to this dose. No dose adjustments were allowed, although doses were withheld in the event of a platelet count greater than 350,000 per cubic millimeter. Patients were followed for 6 weeks after the last dose of study drug.

In collaboration with the investigators, Amgen designed the study, conducted the statistical analyses, and interpreted the data, which Amgen held. The investigators had unrestricted access to the primary data. The academic authors wrote this article, with editing assistance from Amgen; no limitations were imposed by Amgen in the writing of the article. The authors vouch for the completeness and accuracy of the results.

\section{ASSAYS FOR THROMBOPOIETIN AND FOR ANTIBODIES} AGAINST AMG 531 AND THROMBOPOIETIN

Blood samples were drawn at baseline and at specified points under standard conditions. The serum was separated, frozen, and shipped to Amgen for testing. Thrombopoietin levels were measured with the use of a modified, commercially available enzyme-linked immunosorbent assay kit (R\&D Systems). ${ }^{27}$ The presence of antibodies that neutralized AMG 531 or thrombopoietin was determined with the use of a cell-based bioassay. ${ }^{27,28}$ The threshold of detection was approximately $400 \mathrm{ng}$ per milliliter for a control rabbit antihuman AMG 531 antibody and 200 ng per milliliter for a control rabbit antihuman thrombopoietin antibody.

\section{STATISTICAL ANALYSIS}

Demographic characteristics, baseline clinical characteristics, and hematologic and other laboratory values were summarized with the use of descriptive statistics. Enrolled patients were included in all analyses, except that the single patient randomly assigned to the 6- $\mu \mathrm{g}$ dose of AMG 531 in phase 2 was excluded from the platelet-related analyses. The study did not have the statistical power to de- 


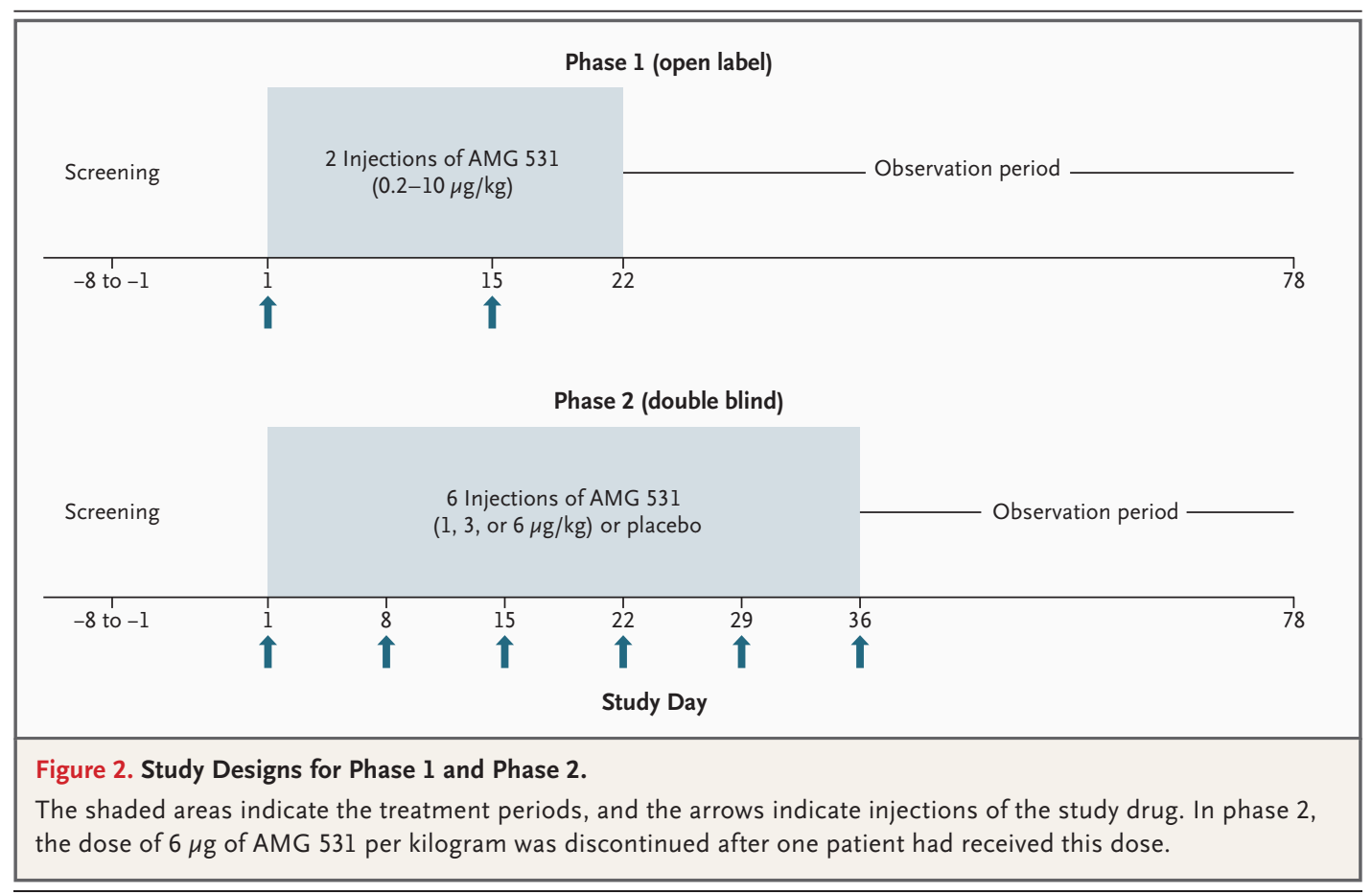

tect a significant difference between dose groups, and no statistical hypothesis testing was performed.

A general linear model was used to investigate the relationship between the peak platelet count and the baseline thrombopoietin level, adjusted for the AMG 531 dose received. Logistic-regression models, adjusted for the AMG 531 dose, were used to determine whether the platelet response was associated with any of the following variables: the baseline serum thrombopoietin level, the baseline platelet count, splenectomy status, and the presence or absence of concurrent corticosteroid therapy.

Platelet counts obtained after the administration of rescue medications were excluded from the efficacy analyses. A rescue medication was defined as any medication, not administered at baseline, that was given to increase platelet counts, or corticosteroids given at a higher dose or frequency than that at baseline.

\section{RESULTS}

\section{STUDY POPULATIONS}

Phase 1

A total of 24 patients with ITP were enrolled in six dose cohorts (4 patients each at AMG 531 dose levels of $0.2,0.5,1,3,6$, and $10 \mu$ g per kilogram).
Table 1 summarizes the demographic and clinical characteristics of the patients at baseline. The majority of the patients were women (17 of 24) and were white (22 of 24); the median age was 45 years. The median platelet count at baseline was 11,000 per cubic millimeter, and the median time since the diagnosis of ITP was 6.2 years. Seven patients (29\%) were receiving corticosteroids, and 19 (79\%) had undergone a splenectomy.

\section{Phase 2}

A total of 21 patients were enrolled in phase 2;

4 were assigned to the placebo group, and 17 to one of the AMG 531 groups (8 each to the $1-\mu \mathrm{g}$ and $3-\mu \mathrm{g}$ groups and 1 to the $6-\mu \mathrm{g}$ group). The placebo and AMG 531 groups were similar with respect to demographic characteristics (Table 1). Fifteen patients were women, and 14 were white; the median age was 49 years. The median platelet count at baseline was 16,000 per cubic millimeter, and the median time since the diagnosis of ITP was 5.2 years. Seven patients (33\%) were receiving corticosteroids, and 14 (67\%) had undergone a splenectomy.

SAFETY

Table 2 summarizes adverse events that occurred in $10 \%$ or more of the patients. Adverse events with an incidence of less than $10 \%$ are provided in the 


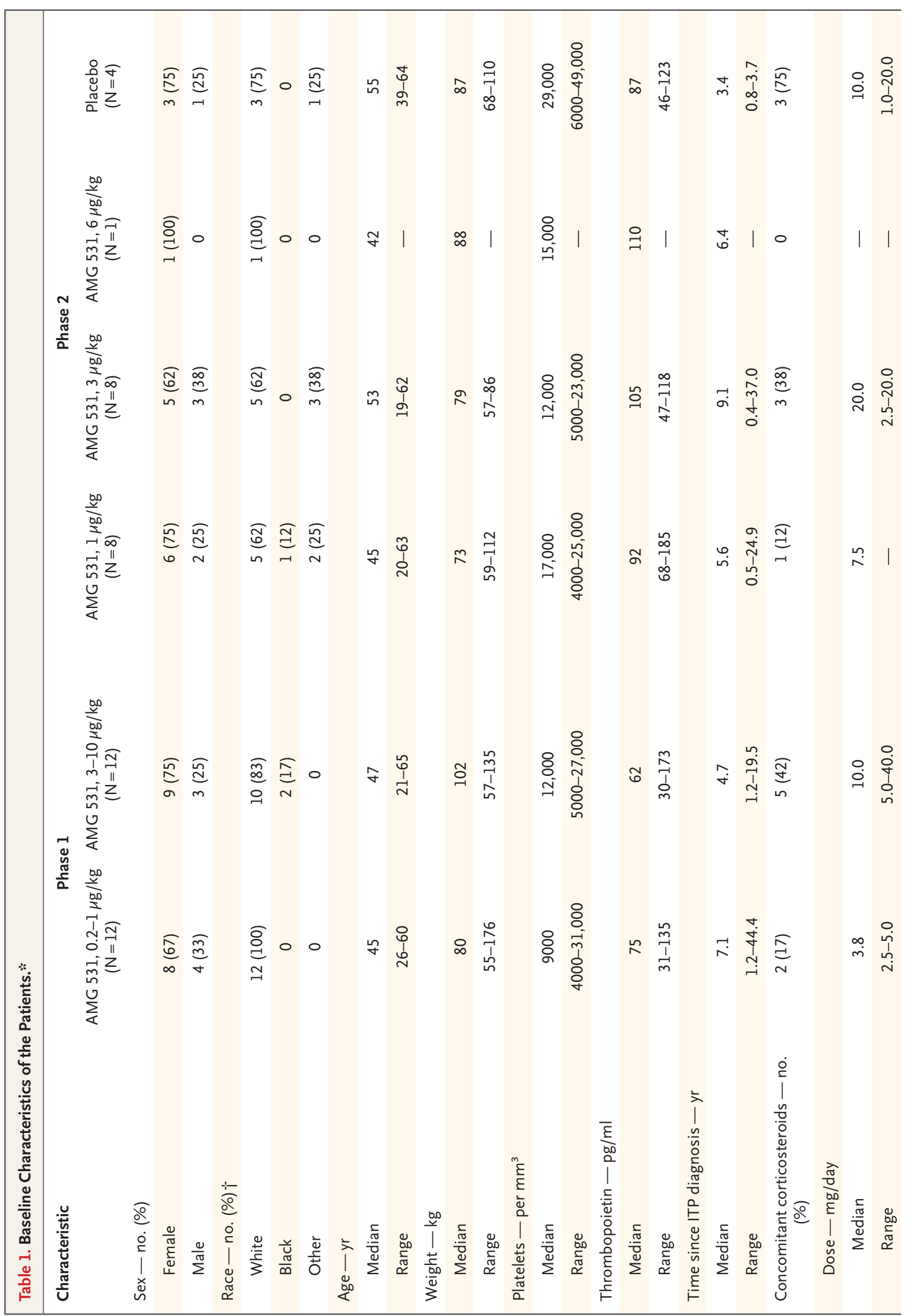




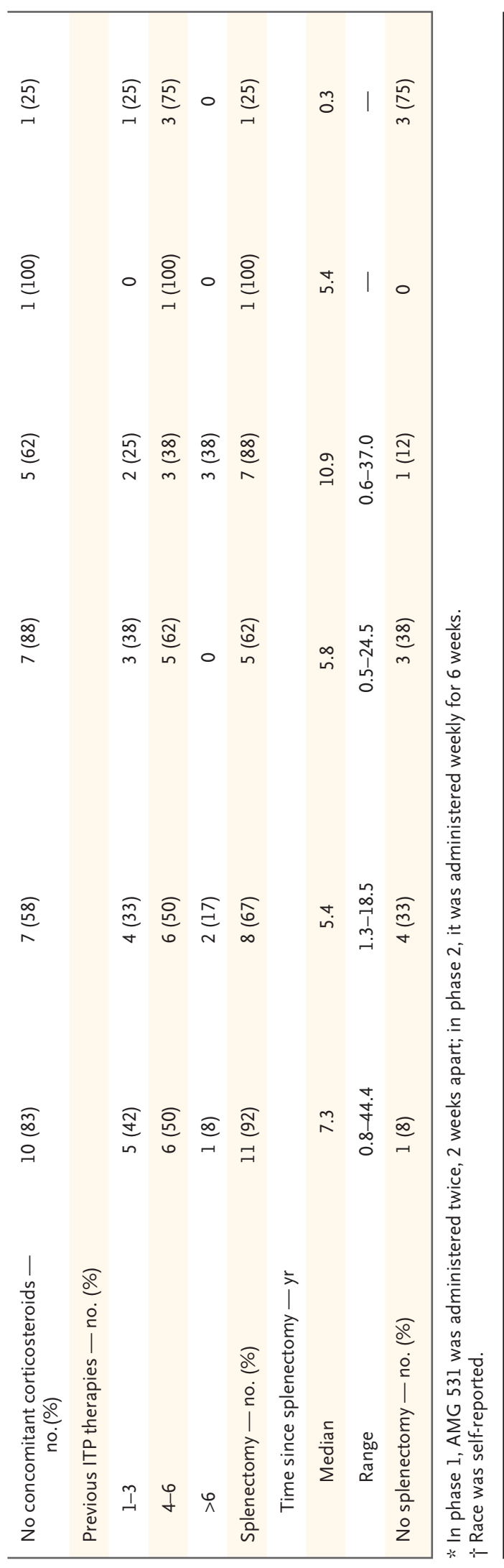

Supplementary Appendix, available with the full text of this article at www.nejm.org.

Phase 1

Since single doses of AMG 531 that were less than $3 \mu \mathrm{g}$ per kilogram did not affect the platelet count in phase 1 , data on adverse events were considered for two combined dose groups: 0.2 to $1 \mu \mathrm{g}$ per kilogram and 3 to $10 \mu \mathrm{g}$ per kilogram. The most frequently reported adverse events were contusions, ecchymosis, or both, which occurred in $67 \%$ of the 24 patients ( 6 of 12 patients receiving 0.2 to $1 \mu \mathrm{g}$ per kilogram and 10 of 12 receiving 3 to $10 \mu \mathrm{g}$ per kilogram), and mild-to-moderate headache, which occurred in $46 \%$ of the patients (6 of 12 receiving 0.2 to $1 \mu \mathrm{g}$ per kilogram and 5 of 12 receiving 3 to $10 \mu \mathrm{g}$ per kilogram).

Serious adverse events were reported in three patients. One patient receiving the $0.2-\mu \mathrm{g}$ dose had grade 3 vertigo, thought by the investigator to be unrelated to AMG 531, and was briefly hospitalized. The second patient, also receiving the $0.2-\mu \mathrm{g}$ dose, had a life-threatening subdural hemorrhage 21 days after the second injection, which was also thought by the investigator to be unrelated to AMG 531. In the third patient, who received the 10- $\mu \mathrm{g}$ dose, the platelet count transiently decreased below the baseline value after the discontinuation of treatment; this event was thought by the investigator to be related to the withdrawal of AMG 531.

\section{Phase 2}

The most frequently reported adverse events in phase 2 were contusions, ecchymosis, or both (occurring in 59\% of the patients in the AMG 531 groups and $75 \%$ of those in the placebo group); epistaxis ( $41 \%$ and $50 \%$, respectively); mild-to-moderate headache (29\% and $0 \%$, respectively), and oral mucosal blistering (also $29 \%$ and $0 \%$, respectively) (Table 2). All patients with oral mucosal blistering had a history of oral bleeding and had bleeding at the time of enrollment. Most bleeding events occurred during the post-treatment period or in patients who did not have a response to the study drug.

Three patients (two who received placebo and one who received AMG 531) had serious adverse events. The two patients in the placebo group had a total of three serious adverse events: one had asthma, and the other had an intracranial hemorrhage and, after splenectomy, popliteal deep-vein 


\begin{tabular}{|c|c|c|c|c|c|}
\hline \multirow[t]{3}{*}{ Adverse Event } & \multicolumn{2}{|c|}{ Phase 1} & \multicolumn{2}{|l|}{ Phase 2} & \multirow{3}{*}{$\begin{array}{c}\text { Total } \\
\text { AMG 531, all doses } \\
(\mathrm{N}=41)\end{array}$} \\
\hline & $\begin{array}{c}\text { AMG } 531,0.2-1 \mu \mathrm{g} / \mathrm{kg} \\
(\mathrm{N}=12)\end{array}$ & $\begin{array}{c}\text { AMG 531, 3-10 } \mu \mathrm{g} / \mathrm{kg} \\
(\mathrm{N}=12)\end{array}$ & $\begin{array}{c}\text { AMG } 531,1 \text { to } 6 \mu \mathrm{g} / \mathrm{kg} \\
(\mathrm{N}=17)\end{array}$ & $\begin{array}{l}\text { Placebo } \\
(\mathrm{N}=4)\end{array}$ & \\
\hline & \multicolumn{4}{|c|}{ number (percent) } & \\
\hline $\begin{array}{l}\text { Contusions, ecchymosis, } \\
\text { or both }\end{array}$ & $6(50)$ & $10(83)$ & $10(59)$ & $3(75)$ & $26(63)$ \\
\hline Headache & $6(50)$ & $5(42)$ & $5(29)$ & 0 & $16(39)$ \\
\hline Petechiae & $3(25)$ & $5(42)$ & $4(24)$ & $1(25)$ & $12(29)$ \\
\hline Epistaxis & $1(8)$ & $2(17)$ & $7(41)$ & $2(50)$ & $10(24)$ \\
\hline Fatigue & $5(42)$ & $3(25)$ & $1(6)$ & 0 & $9(22)$ \\
\hline Oral mucosal blistering & $1(8)$ & $2(17)$ & $5(29)$ & 0 & $8(20)$ \\
\hline Gingival bleeding & $1(8)$ & $2(17)$ & $4(24)$ & $1(25)$ & $7(17)$ \\
\hline Dizziness & $1(8)$ & $3(25)$ & $2(12)$ & $1(25)$ & $6(15)$ \\
\hline $\begin{array}{l}\text { Upper respiratory tract in- } \\
\text { fection (not otherwise } \\
\text { specified) }\end{array}$ & $4(33)$ & $2(17)$ & 0 & 0 & $6(15)$ \\
\hline Excoriation & $1(8)$ & $1(8)$ & $3(18)$ & 0 & $5(12)$ \\
\hline Nausea & $3(25)$ & 0 & $2(12)$ & $1(25)$ & $5(12)$ \\
\hline Arthralgia & $3(25)$ & $1(8)$ & 0 & $1(25)$ & $4(10)$ \\
\hline Peripheral edema & $1(8)$ & $2(17)$ & $1(6)$ & 0 & $4(10)$ \\
\hline $\begin{array}{l}\text { Rash (not otherwise } \\
\text { specified) }\end{array}$ & $3(25)$ & $1(8)$ & 0 & 0 & $4(10)$ \\
\hline $\begin{array}{l}\text { Worsening of thrombocyto- } \\
\text { penia }\end{array}$ & 0 & $1(8)$ & $3(18)$ & 0 & $4(10)$ \\
\hline
\end{tabular}

* In phase 1, AMG 531 was administered twice, 2 weeks apart; in phase 2, it was administered weekly for 6 weeks. Adverse events that occurred in less than $10 \%$ of the patients are listed in the Supplementary Appendix (available with the full text of this article at www.nejm.org).

thrombosis. The patient treated with AMG 531 (3 $\mu$ g per kilogram) had vaginal bleeding with severe but transient worsening of thrombocytopenia 19 days after the discontinuation of AMG 531.

None of the patients had a positive test for antibodies against AMG 531 or thrombopoietin. With the exception of platelet counts, no clinically significant changes were observed in vital signs or in hematologic or serum chemical values.

\section{EFFICACY}

Phase 1

The targeted platelet response was not achieved in the patients who received $0.2,0.5$, or $1 \mu \mathrm{g}$ of AMG 531 per kilogram, with the exception of one patient in the $0.2-\mu \mathrm{g}$ group, who had received rituximab 4 weeks before enrollment. Of the 12 patients who received AMG 531 at a dose of 3, 6, or $10 \mu \mathrm{g}$ per kilogram, however, 4 had platelet counts that reached the targeted range, and 3 additional patients had counts that exceeded 450,000 per cubic millimeter, for a total of 7 patients with peak platelet counts that were 50,000 per cubic millimeter or higher (Fig. 3). The median time to the targeted response ranged from 5 to 8 days. The increase in platelet counts appeared to be dosedependent. Mean peak platelet counts after the first AMG 531 injection were 163,000 per cubic millimeter for $3 \mu \mathrm{g}$ per kilogram, 309,000 per cubic millimeter for $6 \mu \mathrm{g}$ per kilogram, and 746,000 per cubic millimeter for $10 \mu \mathrm{g}$ per kilogram. Median times to peak counts were 11,10 , and 14 days, respectively. Individual peak platelet counts were highly variable at each dose level.

\section{Phase 2}

In one patient, the platelet count increased to 520,000 per cubic millimeter on day 21 . The data review committee closed the highest-dose cohort because of concern that the patient had received the 6- $\mu \mathrm{g}$ dose and that the platelet count exceeded the upper limit of the targeted range. When the study was unblinded, it was confirmed that the patient had received the $6-\mu \mathrm{g}$ dose.

Weekly doses of AMG 531 at 1 and $3 \mu \mathrm{g}$ per 
kilogram increased the platelet count in most patients (Fig. 4). The median time from the first dose to the peak count was 18 days (range, 8 to 43) for $1 \mu \mathrm{g}$ per kilogram, 19 days (range, 8 to 36) for $3 \mu \mathrm{g}$ per kilogram, and 63 days (range, 7 to 78 ) for placebo. The targeted platelet range was reached in seven of eight patients receiving $1 \mu \mathrm{g}$ per kilogram and in three of eight patients receiving $3 \mu \mathrm{g}$ per kilogram; the targeted range was exceeded in an additional two patients receiving the $3-\mu \mathrm{g}$ dose. Overall, in 12 of 16 patients treated with AMG 531 at a weekly dose of 1 or $3 \mu \mathrm{g}$ per kilogram, the targeted range was reached (in 10 patients) or exceeded (in 2 patients), and in 9 of these patients, the platelet response had occurred by the first assessment on day 8 .

In five patients at each dose ( 1 and $3 \mu \mathrm{g}$ per kilogram), the peak platelet count exceeded 100,000 per cubic millimeter. A total of 14 patients treated with AMG 531 had increases in platelet counts of at least 20,000 per cubic millimeter over the baseline count. Individual platelet responses varied in the AMG 531 and placebo groups (Fig. 1 of the Supplementary Appendix). The mean peak platelet counts were 135,000 and 241,000 per cubic millimeter in the groups that received 1 and $3 \mu \mathrm{g}$ per kilogram, respectively, and 81,000 per cubic millimeter in the placebo group; these counts were 8.5, 17, and 2.7 times as high as the baseline counts, respectively. One of four patients in the placebo group had a spontaneous remission; this patient had undergone a splenectomy 3.5 months before entering the study.

No significant relationship was observed between the peak platelet count and the baseline thrombopoietin level. Only the baseline platelet count in phase 1 was predictive of the platelet response (the higher the baseline count, the greater the likelihood of a platelet response; $\mathrm{P}=0.049$ ).

\section{DISCUSSION}

Thrombocytopenia occurs in patients with ITP when the rate of platelet destruction exceeds the ability of the bone marrow to increase platelet production. Autoantibodies from patients with ITP inhibit the production of megakaryocytes in vitro. ${ }^{19,20}$ In addition, apoptotic megakaryocytes have been detected in such patients by means of electron microscopy. ${ }^{19-21}$ Moreover, kinetic data show that platelet production, as measured by platelet turnover, is reduced or normal in approximately two thirds of patients with ITP. ${ }^{16-18}$ Plasma levels

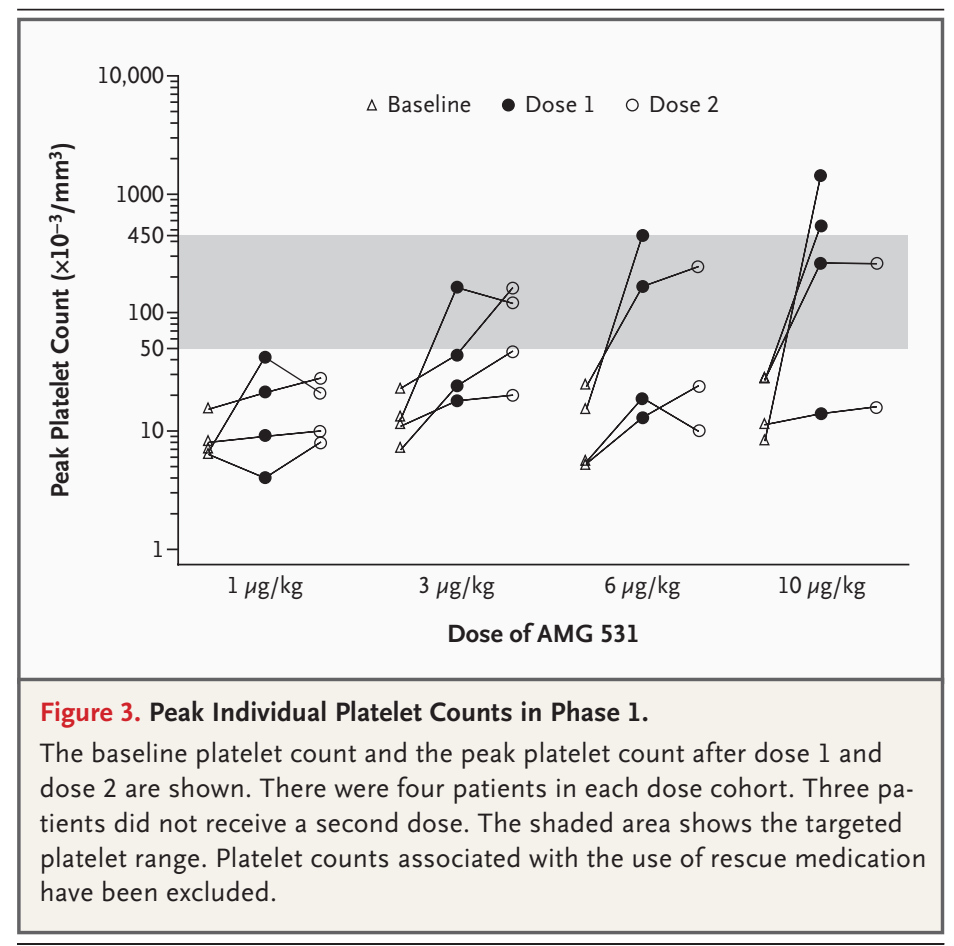

of endogenous thrombopoietin are not elevated in patients with ITP, as they are in patients with thrombocytopenia due to chemotherapy or aplastic anemia ${ }^{8-15}$; the mechanism underlying this phenomenon is thought to be related to clearance of endogenous thrombopoietin by the megakaryocyte and platelet pools. ${ }^{29,30}$ All these findings, which suggest that platelet production in ITP is often impaired, led to the hypothesis that stimulation of platelet production can alleviate the thrombocytopenia.

We evaluated AMG 531 in 41 patients with severe, refractory ITP; 32 of the patients had had no response to conventional treatments, including splenectomy. None of the patients had neutralizing antibodies to AMG 531 or thrombopoietin after as many as six weekly doses of AMG 531. Except for headache and transient post-treatment worsening of thrombocytopenia, all adverse events appeared to be related to the underlying disease. Thirty-nine percent of patients reported mild-tomoderate headache, occurring within 24 hours after the administration of AMG 531 and persisting for several hours, which was controlled with acetaminophen and did not require the discontinuation of treatment.

AMG 531 does not appear to affect the ongoing rate of platelet destruction; in all patients receiving the drug, the platelet count returned to the 


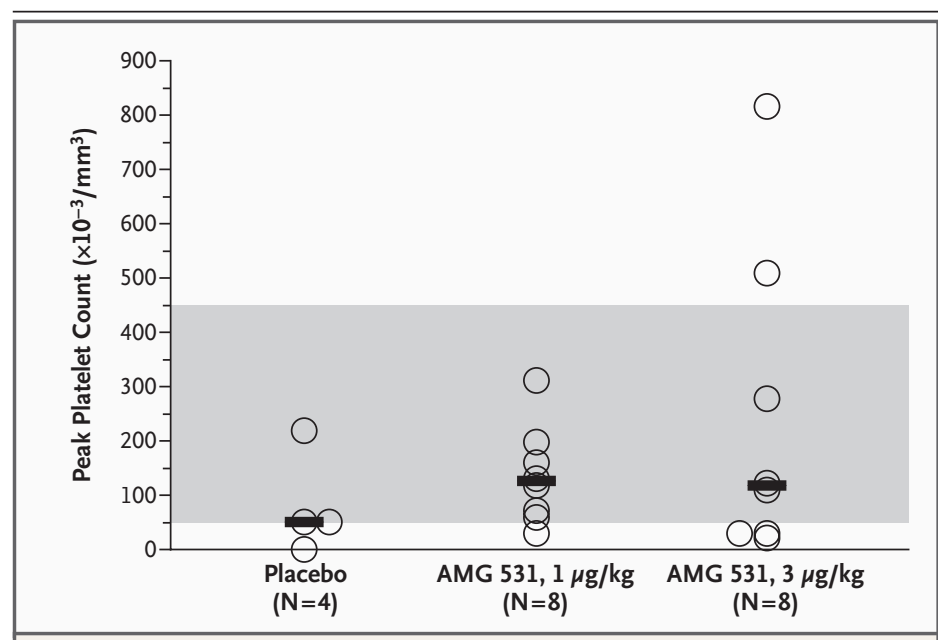

Figure 4. Peak Platelet Counts in Phase 2.

There were eight patients in each of the AMG 531 groups and four patients in the placebo group. Platelet counts have been rounded to the nearest 10 for display purposes. The shaded area shows the targeted platelet range. Platelet counts associated with the use of rescue medication have been excluded. Horizontal bars indicate mean values.

baseline value after the discontinuation of shortterm treatment. In four patients with a platelet response, at least one post-treatment count was less than 10,000 per cubic millimeter and was at least 10,000 per cubic millimeter lower than the baseline value within 4 weeks after the last dose; these low counts persisted for 3 to 17 days. In two of the four patients, rescue treatment with intravenous immune globulin or corticosteroids was administered and was successful. This transient post-treatment worsening of thrombocytopenia had no relationship to the peak platelet count or any other clinical variable that we could evaluate. The phenomenon may be due to increased clearance of endogenous thrombopoietin by the pharmacologically expanded megakaryocyte mass, as demonstrated in studies of animals and humans. ${ }^{29,31}$

Patients completing this and other AMG 531 studies were eligible to enroll in an ongoing, openlabel extension with weekly administration of AMG 531 and dose adjustment based on the platelet count. Preliminary data ${ }^{32}$ indicate that 21 of 26 patients treated for up to 24 weeks had a protocol-defined platelet response to AMG 531 and 12 had a durable response. Two patients who participated in the present study and subsequently entered the extension study were found to have a mild-to-moderate increase in bone marrow reticulin but without collagen fibrosis and with normal cytogenetic findings. ${ }^{33}$ Both patients were asplenic and were receiving relatively high doses of AMG 531 (>10 $\mu \mathrm{g}$ per kilogram), with a minimal response or none. A bone marrow biopsy performed in one of the patients 14 weeks after discontinuation of the treatment showed decreased reticulin deposition. A follow-up biopsy specimen has not yet been obtained for the other patient. In animal models, the increase in reticulin with the administration of PEG-MGDF resolved after discontinuation of the drug, ${ }^{34,35}$ and in patients with leukemia who were treated with thrombopoietin, the increase resolved within 6 weeks after the discontinuation of treatment. ${ }^{36}$

In our study, with the results combined for doses higher than $1 \mu \mathrm{g}$ per kilogram in phase 1 and for the $1-\mu \mathrm{g}$ and $3-\mu \mathrm{g}$ doses in phase 2, 19 of 28 patients had platelet counts that reached or exceeded the targeted range. No complications, including thrombotic events, were reported for patients with platelet counts that exceeded 450,000 per cubic millimeter. In phase 2 , considerable week-to-week fluctuation in platelet counts was observed, even though the administered dose of AMG 531 was not changed. The role of individual dose adjustment will need to be explored in future studies. The mechanism by which AMG 531 increases platelet counts in ITP may involve the prevention of premature megakaryocyte apoptosis, as well as stimulation of megakaryocyte progenitors and megakaryocyte maturation and endomitosis, as has been demonstrated with other thrombopoietic growth factors. ${ }^{37}$

In this dose-finding study, not all patients received the optimal dose of AMG 531 or the optimal schedule of administration. For this reason and because of the short duration of treatment in a relatively small number of patients, the results must be considered preliminary.

Supported by Amgen.

All investigators report having received clinical research support from Amgen for study expenses. Mr. Kelly, Dr. Chen, and Ms. Nichol report being employed by Amgen. Dr. Bussel reports having served on advisory boards for Amgen, GlaxoSmithKline, Baxter, and Talecris; having an equity interest in Amgen and GlaxoSmithKline; and having received lecture fees from Baxter and GlaxoSmithKline. Dr. Kuter reports having served as a consultant to Amgen, GlaxoSmithKline, Pfizer, and Ligand. Dr. George reports having served as a consultant to and having received grant support from Amgen. Dr. McMillan reports having served as a consultant to Amgen, Genzyme, Ligand, and GlaxoSmithKline and having an equity interest in GlaxoSmithKline. Dr. Aledort reports having received lecture fees from Baxter. Dr. Lichtin reports having served on an advisory board for Amgen. Dr. Lyons reports having served as a consultant to and having received grant support from Amgen and Pharmion. Dr. Wiznitzer 
reports having an equity interest in Amgen. No other potential conflict of interest relevant to this article was reported.

We are indebted to the study coordinators and nurses in- volved in phases 1 and 2 of the study; to Matthew Guo, Ph.D. (Amgen), for biostatistical support; and to Michele Vivirito (Amgen) for editorial assistance.
REFERENCES

1. Bottiger LE, Westerholm B. Thrombocytopenia. I. Incidence and aetiology. Acta Med Scand 1972;191:535-40.

2. McMillan R. Chronic idiopathic thrombocytopenic purpura. N Engl J Med 1981; 304:1135-47.

3. Kelton JG, Gibbons S. Autoimmune platelet destruction: idiopathic thrombocytopenic purpura. Semin Thromb Hemost 1982;8:83-104.

4. George J, Harake M, Aster R. Throm bocytopenia due to enhanced platelet de struction by immunologic mechanisms. In: Beutler E, Lichtman MA, Coller BS, Kipps TJ, eds. Williams hematology. 5th ed. New York: McGraw-Hill, 1995:1315-55.

5. George JN, Woolf SH, Raskob GE, et al. Idiopathic thrombocytopenic purpura: a practice guideline developed by explici methods for the American Society of Hematology. Blood 1996;88:3-40.

6. British Committee for Standards in Haematology General Haematology Task Force. Guidelines for the investigation and management of idiopathic thrombocytopenic purpura in adults, children and in pregnancy. Br J Haematol 2003;120:574-96.

7. Cines DB, Bussel JB. How I treat idiopathic thrombocytopenic purpura (ITP) Blood 2005;106:2244-51.

8. Nichol JL. Thrombopoietin levels after chemotherapy and in naturally occurring human diseases. Curr Opin Hemato 1998;5:203-8.

9. Usuki K, Tahara T, Iki S, et al. Serum thrombopoietin level in various hematological diseases. Stem Cells 1996;14:558-65. 10. Kosugi S, Kurata Y, Tomiyama Y, et al. Circulating thrombopoietin level in chronic immune thrombocytopenic purpura Br J Haematol 1996;93:704-6.

11. Chang M, Suen Y, Meng G, et al. Differential mechanisms in the regulation of endogenous levels of thrombopoietin and interleukin-11 during thrombocytopenia insight into the regulation of platelet production. Blood 1996;88:3354-62.

12. Nichol JL, Hokom MM, Hornkohl A et al. Megakaryocyte growth and development factor: analyses of in vitro effects on human megakaryopoiesis and endogenous serum levels during chemotherapy induced thrombocytopenia. J Clin Invest 1995;95:2973-8.

13. Marsh JC, Gibson FM, Prue RL, et al Serum thrombopoietin levels in patients with aplastic anaemia. Br J Haematol 1996; 95:605-10.

14. Emmons RV, Reid DM, Cohen RL, et al. Human thrombopoietin levels are high when thrombocytopenia is due to megakaryocyte deficiency and low when due to increased platelet destruction. Blood 1996, 87:4068-71.
15. Ichikawa N, Ishida F, Shimodaira S, Tahara T, Kato T, Kitano K. Regulation of serum thrombopoietin levels by platelets and megakaryocytes in patients with aplastic anaemia and idiopathic thrombocytopenic purpura. Thromb Haemost 1996;76:156-60. 16. Heyns AD, Lotter MG, Badenhorst $\mathrm{PN}$, et al. Kinetics and sites of destruction of 111Indium-oxine-labeled platelets in idiopathic thrombocytopenic purpura: a quantitative study. Am J Hemato 1982;12:167-77.

17. Heyns Adu P, Badenhorst PN, Lotte MG, Pieters H, Wessels P, Kotze HF. Platelet turnover and kinetics in immune thrombocytopenic purpura: results with autologous 111In-labeled platelets and homologous 51Cr-labeled platelets differ. Blood 1986;67:86-92.

18. Ballem PJ, Segal GM, Stratton JR, Gernsheimer T, Adamson JW, Slichter SJ. Mechanisms of thrombocytopenia in chronic autoimmune thrombocytopenic purpura: evidence of both impaired platelet production and increased platelet clearance. J Clin Invest 1987;80:33-40. 19. McMillan R, Wang L, Tomer A, Nicho J, Pistillo J. Suppression of in vitro megakaryocyte production by antiplatelet autoantibodies from adult patients with chronic ITP. Blood 2004;103:1364-9.

20. Chang M, Nakagawa PA, Williams $\mathrm{SA}$, et al. Immune thrombocytopenic purpura (ITP) plasma and purified ITP monoclonal autoantibodies inhibit megakaryocytopoiesis in vitro. Blood 2003;102 887-95.

21. Houwerzijl EJ, Blom NR, van der Wan JJ, et al. Ultrastructural study shows mor phologic features of apoptosis and paraapoptosis in megakaryocytes from patient with idiopathic thrombocytopenic purpura. Blood 2004;103:500-6.

22. Nomura S, Dan K, Hotta T, Fujimura K, Ikeda Y. Effects of pegylated recombinant human megakaryocyte growth and development factor in patients with idiopathic thrombocytopenic purpura. Blood 2002;100:728-30.

23. Rice L, Nichol JL, McMillan R, Roskos LK, Bacile M. Cyclic immune thrombocytopenia responsive to thrombopoietic growth factor therapy. Am J Hemato 2001;68:210-4

24. Li J, Yang C, Xia Y, et al. Thrombocy topenia caused by the development of an tibodies to thrombopoietin. Blood 2001;98: 3241-8.

25. Basser RL, O'Flaherty E, Green M, et al. Development of pancytopenia with neutralizing antibodies to thrombopoietin after multicycle chemotherapy supported by megakaryocyte growth and development factor. Blood 2002;99:2599-602.
26. Broudy VC, Lin NL. AMG531 stimulates megakaryopoiesis in vitro by binding to Mpl. Cytokine 2004;25:52-60.

27. Aledort LM, Hayward CPM, Chen M-G, Nichol JL, Bussel JB. Prospective screening of 205 patients with ITP, including diagnosis, serological markers, and the relationship between platelet counts, endogenous thrombopoietin, and circulating antithrombopoietin antibodies. Am J Hematol 2004;76:205-13.

28. Wang B, Nichol JL, Sullivan JT. Pharmacodynamics and pharmacokinetics of AMG 531, a novel thrombopoietin receptor ligand. Clin Pharmacol Ther 2004; 76:628-38.

29. Kuter DJ, Beeler DL, Rosenberg RD. The purification of megapoietin: a physiological regulator of megakaryocyte growth and platelet production. Proc Natl Acad Sci U S A 1994;91:11104-8.

30. Scheding S, Bergmann M, Shimosaka A, et al. Human plasma thrombopoietin levels are regulated by binding to platelet thrombopoietin receptors in vivo. Transfusion 2002;42:321-7.

31. Stoffel R, Wiestner A, Skoda RC. Thrombopoietin in thrombocytopenic mice: evidence against regulation at the mRNA level and for a direct regulatory role of platelets. Blood 1996;87:567-73.

32. Bussel JB, Kuter DJ, George JN, et al. Long-term dosing of AMG 531 is effective and well tolerated in thrombocytopenic patients with immune thrombocytopenic purpura. Blood 2005;106:68a. abstract.

33. Stepan DE, Sergis-Deavenport E, Kelly R, et al. Safety profile of AMG 531 in healthy volunteers and in thrombocytopenic patients with immune thrombocytopenic purpura. Blood 2005;106:361a. abstract. 34. Ulich TR, del Castillo J, Senaldi G, et al. Systemic hematologic effects of PEGrHuMGDF-induced megakaryocyte hyperplasia in mice. Blood 1996;87:5006-15. 35. Yanagida $M$, Ide $Y$, Imai $A$, et al. The role of transforming growth factor-beta in PEG-rHuMGDF-induced reversible myelofibrosis in rats. Br J Haematol 1997;99: 739-45.

36. Douglas VK, Tallman MS, Cripe LD, Peterson LC. Thrombopoietin administered during induction chemotherapy to patients with acute myeloid leukemia induces transient morphologic changes that may resemble chronic myeloproliferative disorders. Am J Clin Pathol 2002;117:844-50. 37. Harker LA, Carter RA, Marzec UM, et al. Correction of thrombocytopenia and ineffective platelet production in patients infected with human immunodeficiency virus (HIV) by PEG-rHuMGDF therapy. Blood 1998;92:707a. abstract.

Copyright (c) 2006 Massachusetts Medical Society. 
CORRECTION

AMG 531, a Thrombopoiesis-Stimulating Protein, for Chronic ITP

AMG 531, a Thrombopoiesis-Stimulating Protein, for Chronic ITP . On page 1672, the ninth line of the Results section of the Abstract should have read " 3,6 , and $10 \mu \mathrm{g}$ of AMG 531 per kilogram," rather than " 3 , 6 , and $10 \mu \mathrm{g}$ of AMG 531 per cubic millimeter," as printed. The text has been corrected on the Journal's Web site at www.nejm.org. We regret the error. 